\title{
Lack of association between UBE2E2 gene polymorphism (rs7612463) and type 2 diabetes mellitus in a Saudi population
}

\author{
Khalid Khalaf Alharbi ${ }^{1}$, Imran Ali Khan ${ }^{\circledR}{ }^{凶}$, Yazeed A. Al-Sheikh1, Fawiziah Khalaf Alharbi², \\ Fahad Khalaf Alharbi ${ }^{3}$ and May Salem Al-Nbaheen ${ }^{4,5}$
}

'Department of Clinical Laboratory Sciences, College of Applied Medical Sciences, King Saud University, Riyadh, Kingdom of Saudi Arabia; ${ }^{2 D e-}$ partment of Biology Science, College of Science and Arts, Al-Qassim University, Buraidah, Kingdom of Saudi Arabia; 3Saudi Programme of Internal Medicine, King Fahad Specialist Hospital-Al-Qassim, Kingdom of Saudi Arabia; ${ }^{4 S t e m ~ C e l l ~ U n i t s, ~ A n a t o m y ~ D e p a r t m e n t, ~ C o l l e g e ~ o f ~ M e d i c i n e, ~}$ King Khalid University Hospital, Kingdom of Saudi Arabia; 5 Preparatory Year-Saudi Electronic University, Riyadh, Kingdom of Saudi Arabia

\begin{abstract}
The ubiquitin-conjugating enzyme E2E 2 (UBE2E2) gene plays an important role in insulin synthesis and secretion under conditions in which stress to the endoplasmic reticulum is increased in $\beta$-cells. In this case-control study, we have selected rs7612462 polymorphism within UBE2E2 gene to identify in a Saudi population the type 2 diabetes mellitus (T2DM) subjects. In total, 376 subjects with T2DM and 380 controls were enrolled in this study. We have collected $5 \mathrm{~mL}$ of peripheral blood from each participant for biochemical and molecular analyses. PCR-RFLP was used to generate genotypes at rs7612462 in all of the study subjects. Clinical data and anthropometric measurements of the patients were significantly different from those of the controls $(p<0.05)$. All of the subjects used in this study were non-obese $(25<\mathrm{BMI}<30)$. None of the alleles or genotypes of rs7612462 were associated with T2DM (OR=1.251, 95\% Cl=0.7703-2.034; $p=0.3641$ ). Our data suggest that rs7612462 polymorphism in UBE2E2 does not contribute to T2DM susceptibility in the Saudi population.
\end{abstract}

Key words: T2DM, UBE2E2, PCR-RFLP, Saudi population

Received: 19 May, 2014; revised: 07 October, 2014; accepted: 17 October, 2014; available on-line: 22 October, 2014

\section{INTRODUCTION}

Type 2 Diabetes Mellitus (T2DM) affects nearly 300 million individuals worldwide, and its prevalence $(23.1 \%)$ continues to increase in many countries, including Kingdom of Saudi Arabia (Al-Daghri et al., 2011). Environmental factors such as increased calorie intake, physical inactivity, and obesity are known to contribute to the recent diabetes epidemic (Park et al., 2011). Although the precise mechanisms underlying the development and progression of T2DM have not been elucidated, a combination of multiple genetic and/or environmental factors contribute to the pathogenesis of the disease (Iwata et al., 2012). Impaired insulin secretion and insulin resistance, the two main pathophysiological mechanisms leading to T2DM, have a significant genetic component (Stancakova et al., 2009). Clinical and epidemiological studies have indicated that obesity is a major risk factor for T2DM, as obesity is associated with an increased risk of developing insulin resistance and impaired glucose tolerance (Yamakawa-Kobayashi et al., 2012).

Ubiquitin-conjugating enzyme E2E 2 (UBE2E2) gene on chromosome 3 p24.2 encodes the ubiquitinconjugating enzyme E2E, which plays an important role in insulin synthesis and secretion under conditions where endoplasmic reticulum stress is increased in $\beta$-cells. A single nucleotide polymorphism (SNP; rs7612463) in UBE2E2 was identified as a T2DM susceptibility locus by a genome-wide association study (GWAS) conducted in a Japanese population (Yamauchi et al., 2010). The silent C91227A substitution in intron 3 of UBE2E2 was not significant for T2DM disease. In the present study, we analyzed the relationship between rs7612463 and T2DM susceptibility in a Saudi population.

\section{MATERIAL AND METHODS}

Selection of subjects. 376 T2DM patients and 380 healthy controls used in this study were recruited from King Khalid University Hospital (KKUH), Riyadh, Saudi Arabia. All T2DM subjects had developed the disease more than 5 years prior to their enrollment, and all had a fasting glucose level of $126 \mathrm{mg} / \mathrm{dL}$ or $>7.0 \mathrm{mmol} / \mathrm{L}$, following standards established by the World Health Organization. Individuals with a history of other metabolic disorders apart from T2DM were excluded from the study. Healthy volunteers $(n=380)$ had normal glucose levels, although some had a family history of T2DM. Cases and controls were properly matched for age and gender. All participants gave informed consent and the study was approved by a local ethics committee from KKUH.

Sample collection. A total of $5 \mathrm{~mL}$ of venous blood was collected from each participant; $3 \mathrm{~mL}$ of serum was used for biochemical analysis and $2 \mathrm{~mL}$ was stored with EDTA and used for molecular analysis.

Anthropometric measurements. Participants' weight, height, waist and hip circumference, and blood pressure were measured as previously described (Alharbi et al., 2012). Hypertension was defined as blood pressure measurements $>140 / 90 \mathrm{mmHg}$ with

\footnotetext{
e-mail: imkhan@ksu.edu.sa
}

Abbreviations: T2DM, type 2 diabetes mellitus; UBE2E2, ubiquitinconjugating enzyme E2E 2; GWAS, genome-wide association study; BMI, body mass index; PCR, polymerase chain reaction; SNP, single nucleotide polymorphism 
or without antihypertensives. Body Mass Index (BMI) was calculated as weight (in $\mathrm{kg}$ ) divided by height (in $\mathrm{m}^{2}$ ) squared $\left(\mathrm{kg} / \mathrm{m}^{2}\right)$.

Biochemical parameters. Fasting blood biochemical parameters: HDL-C, triglycerides, total cholesterol, and plasma glucose were measured using an automated clinical chemistry analyzer (Kit provided by KoneLab, Espoo, Finland). Concentrations of LDL-C were calculated using Friedwald's formula. Insulin was quantitated by immunoassay (Medgenix INS-ELISA, Biosource, Belgium). Insulin resistance was measured by the homeostasis model assessment (HOMA-IR), using the formula: Insulin resistance $=$ insulin $(\mu \mathrm{U} /$ $\mathrm{ml}) \times$ glucose $(\mathrm{mmol} / \mathrm{l}) / 22.5$. Dyslipidemia (low levels of HDL-C) was defined as HDL-C levels $<1.03$ $\mathrm{mmol} / \mathrm{l}$ for men and $<1.29 \mathrm{mmol} / \mathrm{l}$ for women (Alharbi et al., 2012).

DNA extraction and UBE2E2 genotyping. Genomic DNA was extracted from peripheral blood leukocytes using a Norgen DNA extraction kit (Norgen Biotek Corp, Canada). DNA samples were stored at $-80^{\circ} \mathrm{C}$. Genotyping of $\mathrm{rs} 7612463$ was performed by Polymerase Chain Reaction (PCR) using the Norgen $2 \mathrm{X}$ master mix, followed by the application of the Restriction Fragment Length Polymorphism (RFLP) method and agarose gel electrophoresis. Specific primers were designed using the primer 3 plus software: forward primer, 5'-TCAAGACGTGGCTCATCTGT-3'; reverse primer, 5'-ATGTCACT'TGCAGCCCTCTT -3'. Primers were synthesized by Bioserve Biotechnology, (Hyderabad, India). For PCR reactions, DNA was denatured at $95^{\circ} \mathrm{C}$ for $5 \mathrm{~min}$, followed by 35 cycles of $95^{\circ} \mathrm{C}$ for $30 \mathrm{sec}, 66^{\circ} \mathrm{C}$ for $30 \mathrm{sec}, 72^{\circ} \mathrm{C}$ for $45 \mathrm{sec}$, and a final extension step at $72^{\circ} \mathrm{C}$ for 5 minutes. For RFLP analysis, $15 \mu \mathrm{L}$ of the PCR product was incubated with $1.0 \mu \mathrm{L}$ of AluI [AG ${ }^{\downarrow} \mathrm{CT}$ ] $(10 \mathrm{U} /$ $\mu \mathrm{L}$, New England BioLabs, USA) in a final volume of $20 \mu \mathrm{L}$ for 2 hours at $65^{\circ} \mathrm{C}$. Digested products were run on $2 \%$ agarose for 60 minutes at $250 \mathrm{~V}$. Bands were analyzed using a transilluminator.

Statistical analysis. All values are expressed as mean \pm S.D. Results were analyzed by $t$-test, with a $p$ value threshold of 0.05 . Genotypic and allelic frequen- cies were compared between T2DM cases and control subjects. Allele frequencies were estimated by the gene counting method, and the Chi square test was used to identify departures from Hardy-Weinberg equilibrium. Statistical significance was examined by two-sided tests, and statistical analyses were performed with SPSS version 16.0 software.

\section{RESULTS}

\section{Patient Characteristics}

Clinical and anthropometric data for control and T2DM patients are shown in Table 1. Results revealed that Anthropometric measurements, including hip circumference were also significantly higher in T2DM patients were significantly older than controls $(p<0.05)$. T2DM subjects appear to have higher levels of fasting glucose and lipids (TG, TC, HDL-C and LDL-C), as well as higher systolic and diastolic blood pressures but not HDL-C $(p<0.05)$. BMI and waist circumference were not different between cases and controls $(p>0.05)$.

\section{Allele and genotype frequencies at rs7612463 in cases and controls}

All three potential genotypes, AA, AC, and CC, were detected at rs7612463 in UBE2E2 gene. Their frequencies in T2DM cases and controls are shown in Table 2. The distribution of genotypes at rs7612463 deviates Hardy-Weinberg equilibrium and was not significantly different between cases and controls ( $p>0.05$; Table 3$)$. rs7612463 AA genotype and A allele (CA+AA vs. CC) were not associated with increased risk of T2DM (OR = $1.249,95 \%$ CI $=0.7056-2.21 ; p=0.4448)$. Likewise, under the additive model, the A allele was not significantly associated with an increased risk of T2DM $(\mathrm{OR}=1.251$, $95 \%$ CI $=0.7703-2.034 ; p=0.3641)$. In addition, there was no evidence for an association between rs7612463 and risk of T2DM under the recessive model (AA vs. $\mathrm{CA}+\mathrm{CC})$ or the co-dominant model (CA vs. CC+AA) $(\mathrm{OR}=1.223,95 \% \mathrm{CI}=0.6072-2.465 ; p=0.5720)$.

Table 1. Demographic characteristics of the study population.

\begin{tabular}{|c|c|c|c|}
\hline & T2DM $(n=376)$ & Controls $(n=380)$ & $p$ \\
\hline Age (Years) & $50.63 \pm 10.39$ & $46.06 \pm 7.66$ & $<0.0001$ \\
\hline Body mass index $\left(\mathrm{kg} / \mathrm{m}^{2}\right)$ & $29.51 \pm 5.92$ & $29.19 \pm 5.53$ & 0.18 \\
\hline Sex: Male/Female & $(59.8 \%) /(40.2 \%)$ & $(53.2 \%) /(46.8 \%)$ & 0.003 \\
\hline $\mathrm{SBP}(\mathrm{mmHg})$ & $123.94 \pm 11.74$ & $114.96 \pm 7.84$ & 0.0001 \\
\hline $\mathrm{DBP}(\mathrm{mmHg})$ & $78.21 \pm 7.43$ & $75.78 \pm 20.26$ & 0.01 \\
\hline Waist (cms) & $94.3 \pm 22.36$ & $91.2 \pm 20.26$ & 0.055 \\
\hline Hip (cms) & $104.83 \pm 21.44$ & $94.46 \pm 7.80$ & $<0.0001$ \\
\hline FBS (mmol/L) & $9.89 \pm 5.22$ & $5.25 \pm 0.60$ & $<0.0001$ \\
\hline Triglycerides (mmol/L) & $2.23 \pm 1.65$ & $1.61 \pm 0.86$ & $<0.0001$ \\
\hline Cholesterol (mmol/L) & $5.63 \pm 1.26$ & $5.05 \pm 0.97$ & 0.001 \\
\hline HDL-cholesterol (mmol/L) & $0.93 \pm 0.75$ & $0.63 \pm 0.23$ & $<0.0001$ \\
\hline LDL-cholesterol (mmol/L) & $3.79 \pm 1.07$ & $3.68 \pm 0.85$ & 0.0008 \\
\hline Glucose (mmol/L) & $9.4 \pm 1.5$ & $8.69 \pm 1.82$ & 0.0001 \\
\hline Insulin ( $\mu \mathrm{U} / \mathrm{ml})$ & $16.2 \pm 2.2$ & $12.3 \pm 1.7$ & 0.0006 \\
\hline HOMA-IR & $7.1 \pm 2.4$ & $3.15 \pm 1.9$ & $<0.0001$ \\
\hline
\end{tabular}


Table 2. Genotype and allele frequencies at rs7612463.

\begin{tabular}{|c|c|c|c|c|c|c|}
\hline rs7612463 & T2DM Cases $(n=376)$ & Controls $(n=380)$ & OR & $95 \% \mathrm{Cl}$ & $x^{2}$ & $p$ value \\
\hline CC & $348(92.6 \%)$ & 357 (94\%) & Reference & & & \\
\hline CA & $18(4.8 \%)$ & 15 (3.9\%) & 1.231 & $(0.61-2.48)$ & 0.33 & 0.56 \\
\hline AA & $10(2.6 \%)$ & $8(2.1 \%)$ & 1.281 & $(0.50-3.28)$ & 0.26 & 0.60 \\
\hline$C A+A A$ & $28(7.4 \%)$ & $23(6)$ & 1.249 & $(0.70-2.21)$ & 0.58 & 0.44 \\
\hline C & $714(0.95)$ & $729(0.96)$ & Reference & & & \\
\hline A & $38(0.05)$ & $31(0.04)$ & 1.252 & $(0.77-2.03)$ & 0.82 & 0.36 \\
\hline
\end{tabular}

\section{DISCUSSION}

Availability of molecular studies by PCR-RFLP, DNA sequencing and UBE2E2 gene allows accurate diagnosis and characterization in T2DM subjects. In this casecontrol study, we genotyped in Saudi T2DM subjects at rs7612463 in UBE2E2 gene. T2DM is a complex disease that is categorized by insulin resistance and impaired $\beta$-cell function. Prevalence of T2DM is increasing at an alarming rate, in parallel with expanding obesity rates worldwide, making it a major public health concern. Search for genetic determinants of T2DM has changed dramatically. Linkage analysis and small-scale candidate gene studies were highly successful in the identification of risk genes such as PPARG and KCNJ11, which are strongly implicated in T2DM susceptibility. Large scale association analysis, including GWAS, was the first completion of the human genome sequence, which in turn led to the detailed maps of common single nucleotide polymorphism (SNPs) and patterns of linkage disequilibrium (Wheeler et al., 2011).

GWASs conducted in Japanese T2DM cohorts have identified KCNQ1, UBE2E2, C2CD4A-C2CD4B, and ANK1 as susceptibility loci (Yamauchi et al., 2010; Unoki et al., 2008; Yasuda et al., 2008; Imamura et al., 2012), all of which, except for UBE2E2, have also been associated with T2DM in European populations (Yamauchi et al., 2010; Unoki et al., 2008; Yasuda et al., 2008; Imamura et al., 2012). This illustrates the importance of carrying out GWASs in multiple ethnic populations to identify the risk loci that are either ethnicity-specific or common to many populations (Fukuda et al., 2012).

UBE2E2 gene has been reported to be expressed in human pancreas, liver, muscle, and adipose tissues, as well as in a cultured insulin secreting cell line. It has been reported that the ubiquitin proteasome system plays a pivotal role in maintaining normal insulin biosynthesis, secretion, and signaling, especially under conditions that increase the stress in the endoplasmic reticulum of pancreatic $\beta$-cells (Hartley et al., 2009).

Earlier studies showed that proteasome inhibition by pharmacological inhibitors reduced proinsulin biosynthesis (Kitiphongspattana et al., 2005), the molecules in-

Table 3. Statistical analysis conducted for rs7612463.

\begin{tabular}{ll}
\hline Genotypes & Odds ratio and pvalue with $95 \% \mathrm{Cl}$ \\
\hline AA Vs CA+CC & $\mathrm{OR}=1.27,95 \% \mathrm{Cl}=0.4959-3.255 ; p=0.6172$ \\
\hline CA+AA Vs CC & $\mathrm{OR}=1.249,95 \% \mathrm{Cl}=0.7056-2.21 ; p=0.4448$ \\
\hline CA Vs CC +AA & $\mathrm{OR}=1.223,95 \% \mathrm{Cl}=0.6072-2.465 ; p=0.5720$ \\
\hline A Vs C & $\mathrm{OR}=1.251,95 \% \mathrm{Cl}=0.7703-2.034 ; p=0.3641$ \\
\hline
\end{tabular}

volved in insulin secretion (Kawaguchi et al., 2006), and glucose stimulated insulin secretion (Lopez-Avalos et al., 2006; Matthews et al., 1985), whereas other investigators reported that proteasome inhibitors enhanced acute glucose induced insulin secretion in isolated rat islets (Warton et al., 2004). Both results suggest that the ubiquitin proteasome system plays an important role in insulin secretion.

Yamauchi and coworkers (2010) showed that in UBE2E2 gene Fasting plasma glucose and Insulin levels of CC+CA genotypes $(n=846)$ showed a significantly lower Homa- $\beta$ (Homeostasis model assessment of $\beta$-cell function) than those with the risk of AA genotypes $(n=26)$.

In this study, we investigated the potential association between rs7612463 in UBE2E2 gene and the risk of T2DM in a Saudi population. Our study on rs7612463 polymorphism was carried out among the Saudi population, although this polymorphism was identified from the GWAS studies in Japanese population. Consistent with our results, rs7612463 was not previously associated with T2DM in a Japanese population (Yamauchi et al., 2010). We observed the distribution of the three genotypes to be $92.6 \%, 4.8 \%$ and $2.6 \%$ in the T2DM cases and $94 \%, 3.9 \%$ and $2.1 \%$ in the controls. A number of studies have investigated the association between rs7612463 and T2DM risk (Yamakawa-Kobayashi et al., 2012; Yamauchi et al., 2010). However, results from these studies are conflicting. This is the first study to carry out an association study of rs7612463 and T2DM in a Saudi population as well as in Arab countries. A limitation of the current study includes the selection of a single specific SNP. Moreover, we conducted the current study with a single rs number and did not consider the interactions between the gene and its protein, what would require further studies.

In conclusion, our results revealed that rs 7612463 was not associated with T2DM which were non-obese. Additional studies of rs7612463 in T2DM patient cohorts from other ethnic backgrounds should be conducted to further validate our results. Functional studies remain to be performed to establish the precise roles of these variants and pathways.

\section{Conflict of Interests}

We declare that there is no conflict of interest.

\section{Authors Contribution}

Design of the work: AKK, and IAK. Sample collection and genotyping: IAK, AYA and AMS. Statistical analysis: AFF and AFF. Manuscript written, and edited: $\mathrm{AKK}$ and IAK. 


\section{Acknowledegments}

The authors would like to extend their sincere appreciation to the Deanship of Scientific Research at King Saud University for its funding of this research through the Research Group Project no RGP-VPP-244.

\section{REFERENCES}

Al-Daghri NM, Al-Attas OS, Alokail MS, Alkharfy KM, Yousef M, Sabico SL, Chrousos GP (2011) Diabetes mellitus type 2 and other chronic non-communicable diseases in the central region, Saudi Arabia (Riyadh cohort 2): a decade of an epidemic. BMC Med 20: 76.

Park KS (2011) The search for genetic risk factors of type 2 diabetes mellitus. Diabetes Metab 31: 2-22.

Iwata M, Maeda S, Kamura Y, Takano A, Kato H, Murakami S, Higuchi K, Takahashi A, Fujita H, Hara K, Kadowaki T, Tobe K (2012) Genetic risk score constructed using 14 susceptibility alleles for type 2 diabetes is associated with the early onset of diabetes and may predict the future requirement of insulin injections among Japanese individuals. Diabetes Care 35: 1763-1770.

Stancakova A, Kuulasmaa T, Paananen J, Jackson AU, Bonnycastle LL, Collins FS, Boehnke M, Kuusisto J, Laakso M (2009) Association of 18 confirmed susceptibility loci for type 2 diabetes with indices of insulin release, proinsulin conversion, and insulin sensitivity in 5,327 nondiabetic Finnish men. Diabetes 58: 2129-2136.

Yamakawa-Kobayashi K, Natsume M, Aoki S, Nakano S, Inamori T, Kasezawa N, Goda T(2012) The combined effect of the T2DM susceptibility genes is an important risk factor for T2DM in nonobese Japanese: a population based case-control study. BMC Med Genet 24: 13-11.

Yamauchi T, Hara K, Maeda S, Yasuda K, Takahashi A, Horikoshi M, Nakamura M, Fujita H, Grarup N, Cauchi S, Ng DP, Ma RC, Tsunoda T, Kubo M, Watada H, Maegawa H, Okada-Iwabu M, Iwabu M, Shojima N, Shin HD, Andersen G, Witte DR, Jørgensen T, Lauritzen T, Sandbaek A, Hansen T, Ohshige T, Omori S, Saito I, Kaku K, Hirose H, So WY, Beury D, Chan JC, Park KS, Tai ES, Ito C, Tanaka Y, Kashiwagi A, Kawamori R, Kasuga M, Froguel P, Pedersen O, Kamatani N, Nakamura Y, Kadowaki T (2010) A genome-wide association study in the Japanese population identifies susceptibility loci for type 2 diabetes at UBE2E2 and C2CD4AC2CD4B. Nat Genet 42: 864-868.
Alharbi KK, Khan IA, Syed R (2013) Circulating C5L2 gene polymorphism is associated with type 2 diabetes mellitus in Saudi population. Mol Biol Rep 40: 6323-6327.

Wheeler E, Barroso I (2011) Genome-wide association studies and type 2 diabetes. Brief Funct Genomics 10: 52-60.

Unoki H, Takahashi A, Kawaguchi T, Hara K, Horikoshi $\mathrm{M}$ et al. (2008) SNPs in KCNQ1 are associated with susceptibility to type 2 diabetes in East Asian and European populations. Nat Genet 40: 1098-1102.

Yasuda K, Miyake K, Horikawa Y, Hara K, Osawa H et al. (2008) Variants in KCNQ1 are associated with susceptibility to type 2 diabetes mellitus. Nat Genet 40: 1092-1097.

Imamura M, Maeda S, Yamauchi T, Hara K, Yasuda K et al. (2012) A single-nucleotide polymorphism in ANK1 is associated with susceptibility to type 2 diabetes in Japanese populations. Hum Mol Genet 10: 1093-1113.

Fukuda H, Imamura M, Tanaka Y, Iwata M, Hirose H, Kaku K, Maegawa $\mathrm{H}$, Watada $\mathrm{H}$, Tobe $\mathrm{K}$, Kashiwagi A, Kawamori $\mathrm{R}$, Maeda S (2012) A single nucleotide polymorphism within DUSP9 is associated with susceptibility to type 2 diabetes in a Japanese population. PLoS One 7: e46263.

Hartley T, Brumell J, Volchuk A (2009) Emerging roles for the ubiquitin-proteasome system and autophagy in pancreatic beta-cells. Am J Physiol Endocrinol Metab 296: E1-E10.

Kitiphongspattana K, Mathews CE, Leiter EH, Gaskins HR (2005) Proteasome inhibition alters glucose-stimulated (pro) insulin secretion and turnover in pancreatic $\{$ beta\}-cells. J Biol Chem 280: 15727-15734.

Kawaguchi M, Minami K, Nagashima K, Seino S (2006) Essential role of ubiquitin-proteasome system in normal regulation of insulin secretion. J Biol Chem 281: 13015-13020.

Lopez-Avalos, Duvivier-Kali VF, Xu G, Bonner-Weir S, Sharma A, Weir GC (2006) Evidence for a role of the ubiquitin-proteasome pathway in pancreatic islets. Islets. Diabetes 55: 1223-1231.

Matthews DR, Hosker JP, Rudenski AS, Naylor BA, Treacher DF, Turner RC (1985) Homeostasis model assessment: insulin resistance and beta-cell function from fasting plasma glucose and insulin concentrations in man. Diabetologia 28: 412-419.

Warton K, Foster NC, Gold WA, Stanley KK (2004) A novel gene family induced by acute inflammation in endothelial cells. Gene 342: 85-95. 